\title{
Failure behaviour of self-reinforced polypropylene at and below room temperature
}

\author{
Y. Swolfs *, W. Van den fonteyne, J. Baets, I. Verpoest \\ Department of Materials Engineering, KU Leuven, Kasteelpark Arenberg 44, Belgium
}

\section{A R T I C L E I N F O}

\section{Article history:}

Received 18 April 2014

Received in revised form 3 June 2014

Accepted 7 June 2014

Available online 14 June 2014

\section{Keywords:}

A. Polymer-matrix composites (PMCs)

B. Impact behaviour

B. Mechanical properties

Self-reinforced composites

\begin{abstract}
A B S T R A C T
Self-reinforced polypropylene is a very tough material. It is even thought that its impact resistance increases with decreasing temperature. This was investigated by examining the constituent tapes and matrix. Tensile tests on both drawn polypropylene tapes and self-reinforced polypropylene were similar: the stiffness increased and the failure strain slightly decreased at low temperatures. The matrix, however, embrittled below room temperature due to the glass transition. In contrast with literature data on Izod impact resistance, the penetration impact resistance did not increase at low temperatures. At lower temperatures, the damaged area after non-penetration impact was significantly reduced. This was caused by a change in the damage mode from tape-matrix debonding to matrix cracking, as the matrix went through its glass transition. These conclusions provide the first understanding of the failure behaviour of self-reinforced polypropylene below room temperature, and can be exploited to further optimise the excellent impact resistance of self-reinforced polymers.
\end{abstract}

(c) 2014 Elsevier Ltd. All rights reserved.

\section{Introduction}

Fibre-reinforced polymers are known for their exceptionally high specific stiffness and strength, but often lack toughness. A promising solution is the use of self-reinforced polymers, in which reinforcement and matrix are made from the same polymer. The commercially most important example is self-reinforced polypropylene (SRPP) [1-3].

The starting material for SRPP is highly drawn polypropylene (PP) fibre or tape. The drawing process enhances the molecular orientation of the PP, which improves the mechanical properties in the drawing direction [4,5]. These fibres or tapes are then woven in the preferred configuration [6-8] and compacted at elevated temperature and pressure into a self-reinforced sheet. Several techniques exist for creating the matrix. The most important techniques are film stacking $[9,10]$, co-extrusion $[7,11,12]$ and hot compaction $[1,6,13-17]$. The focus here is on the hot compaction process. In this process, a homopolymer tape is used. By selecting the correct combination of temperature and pressure, it succeeds in selectively melting the outer sheath of the drawn tapes. This molten material then recrystallises to create the matrix $[1,18]$.

\footnotetext{
* Corresponding author. Tel.: +32 163736 16; fax: +32 16321990.

E-mail addresses: yentl.swolfs@mtm.kuleuven.be(Y.Swolfs),pywvdf@leeds.ac.uk (W.Van den fonteyne), joris.baets@mtm.kuleuven.be(J. Baets), ignaas.verpoest@mtm.
} kuleuven.be (I. Verpoest).
The final SRPP properties depend on the properties of the two components, just as in classical fibre-reinforced polymers [13]. The properties of the oriented PP tapes before compaction strongly depend on the conditions of the drawing process, whereas the properties of the PP matrix and thus the tape-to-tape and interlayer bonding in the compacted sheet depend on the conditions of the hot compaction process [5,6,12].

The tape properties are mainly influenced by the draw ratio and temperature. In general, the higher the draw ratio, the higher the stiffness and strength of the final tapes will be. There is, however, a maximum attainable draw ratio, which is determined by the nature of the bonds and the chain extension in the polymer [19]. This maximum draw ratio depends on the molecular weight of the polymer $[5,20]$. The yield stress and the failure strain of the tapes depend on the drawing temperature. A lower drawing temperature results in a lower yield stress and a larger failure strain, as the drawing temperature determines the crystal structure variations during the drawing process. This has been investigated in detail by Schimanski et al. [5]. Furthermore, annealing treatments have been shown to affect the thermal and mechanical properties of drawn PP tapes [20].

The compaction temperature, pressure and time determine the degree to which the tape properties are maintained as well as the tape-to-tape and interlayer bonding strength in the final SRPP [6]. In case of woven SRPP, the mechanical properties in the $\left[0^{\circ} / 90^{\circ}\right]$ direction are determined by the tape properties after hot 
compaction, while the properties in the $\left[ \pm 45^{\circ}\right]$ direction are dominated by the consolidation quality and the matrix fraction. A higher processing temperature and/or pressure leads to a higher interfacial strength [7]. A well-chosen processing temperature leads to full consolidation while retaining the good mechanical properties of the PP tapes. The processing also anneals the tapes, which has been proven to further refine the crystal structure [6].

The processing parameters and hence the properties of the final self-reinforced polymer may be chosen differently in function of the application. As the dominant failure modes in impact are tape fracture, tape-matrix debonding and delamination, the penetration impact energy of SRPP benefits from a lower processing temperature and/or pressure, because this facilitates delaminations. SRPP that is optimised for penetration impact, however, may not possess adequate interfacial properties to serve as a viable structural component [12]. SRPP outperforms glass or natural fibre reinforced PP in terms of impact resistance. Commercial SRPP even shows an increase of 50\% in notched Izod impact resistance at a temperature of $-40{ }^{\circ} \mathrm{C}$, compared to at room temperature $[1,21]$.

The influence of the drawing process parameters on the mechanical properties of the PP tapes and the influence of the processing parameters on the mechanical properties of the final SRPP were extensively studied [4,5,22-24]. However, these studies do not explain the impact behaviour of SRPP at low temperature. In particular, its increasing toughness at low temperature is unique for polymeric materials. In this paper, the SRPP failure behaviour at different temperatures is analysed with a focus on impact behaviour. The mechanical properties of the matrix and the drawn PP tapes are studied separately at and below room temperature, to analyse the influence of temperature on the different components of the SRPP. This leads to the first explanation of the impact resistance of SRPP below room temperature.

\section{Materials and methods}

\subsection{Materials}

Drawn polypropylene (PP) tapes and non-drawn PP films of the same PP grade were kindly provided by Propex Fabrics $\mathrm{GmbH}$ (Gronau, Germany). The non-drawn PP film is $20 \mu \mathrm{m}$ thick and can be considered to be the same material as the matrix in the final SRPP. The tapes were also provided in a twill $2 / 2$ weave with an areal density of $130 \mathrm{~g} / \mathrm{m}^{2}$.

\subsection{Hot compaction}

The production method is a combination of hot compaction and film stacking $[25,26]$. Eight layers of the PP tape fabric alternated with PP film were stacked and placed in between aluminium cover plates. This assembly was inserted into a Fontijne Grotnes LabPro 400 press, which was preheated to $188^{\circ} \mathrm{C}$. This temperature was maintained for $5 \mathrm{~min}$, after which the press was cooled down to $40{ }^{\circ} \mathrm{C}$ in $4 \mathrm{~min}$. The pressure was kept constant at $40 \mathrm{bar}$. More information on how these processing conditions were optimised can be found in [27].

Samples for peel tests were made by stacking 4 layers of PP tape fabric alternated with PP films. A $13 \mu \mathrm{m}$ Upilex release film was inserted between the second and third fabric and the same processing conditions were applied.

To be able to compare the toughness of SRPP with that of isotropic PP, isotropic PP plates were produced from the non-drawn PP film. To produce these plates, the same hot compaction conditions were applied to a stack of PP films.

\subsection{Annealing treatment}

To study the evolution of the properties of the PP tapes inside SRPP during the hot compaction process, an annealing treatment was applied to the individual PP tapes. To avoid shrinkage of the tapes, they were kept under tension during the treatment. The tapes were drawn through a stainless steel die, and were in contact with the die for $10 \mathrm{~s}$. The temperature was measured in the middle of the die with a thermocouple. Five different temperatures were used for annealing: $163{ }^{\circ} \mathrm{C}, 176{ }^{\circ} \mathrm{C}, 182^{\circ} \mathrm{C}, 186^{\circ} \mathrm{C}$ and $190^{\circ} \mathrm{C}$. Higher temperatures were not possible without melting the tapes.

\subsection{Tensile tests}

Tensile tests were performed using an Instron 5985 at $20^{\circ} \mathrm{C}$, $-10^{\circ} \mathrm{C}$ and $-40^{\circ} \mathrm{C}$ in a chamber cooled using liquid nitrogen. The tests at $20^{\circ} \mathrm{C}$ were performed at a deformation rate of $25 \%$ / min, using a load cell of $1 \mathrm{kN}$. Due to restrictions of the cooling chamber, a $30 \mathrm{kN}$ load cell was used for the lower temperatures.

Three types of materials were tested: matrix, tapes and hot compacted SRPP. At least six samples were tested for each material type. For the matrix, dog bone samples with $60 \mathrm{~mm}$ gauge length, $10 \mathrm{~mm}$ width and $1 \mathrm{~mm}$ thickness were tested. For the tapes, the gauge length was $100 \mathrm{~mm}$. Paper tape was wrapped around the tape in the clamping region to ensure proper gripping. For the SRPP, rectangular samples of $250 \times 25 \times 1.3 \mathrm{~mm}$ were tested. The strain in the matrix samples was measured using a contact extensometer, while an optical extensometer was used for the tapes and SRPP samples.

The stiffness was calculated between $0.1 \%$ and $0.3 \%$ strain. The energy absorbed by the sample during the test was calculated from the integral of the stress in the sample over the strain from the start of the test until the stress drops to $40 \%$ of the maximum stress, resulting in an energy per volume.

\subsection{Peel strength tests}

To assess the interlayer bonding, T-peel tests were performed according to ASTM D1876. The samples were cut down to a width of $25 \mathrm{~mm}$ width, with an unbonded length of $76 \mathrm{~mm}$ width. Samples from three different plates were tested in a random fashion. The unbonded sample ends were pulled apart at a displacement rate of $254 \mathrm{~mm} / \mathrm{min}$ in an Instron 5985 tensile machine, equipped with a $30 \mathrm{kN}$ load cell. The tests were performed at $20^{\circ} \mathrm{C},-10^{\circ} \mathrm{C}$ and $-40^{\circ} \mathrm{C}$ in a cooling chamber. At least 11 samples were tested for each temperature. The peel strength was calculated as the average load per width of the sample for the first $127 \mathrm{~mm}$ of displacement after the initial load peak.

\subsection{Falling weight impact tests}

The impact behaviour of SRPP was investigated by performing falling weight impact tests on a Fractovis CEAST 6789. This device has a hemispherical striker with a $20 \mathrm{~mm}$ diameter. The sample was clamped at a pressure of 9 bar. The tests were performed at $20^{\circ} \mathrm{C},-10^{\circ} \mathrm{C}$ and $-40^{\circ} \mathrm{C}$ using liquid nitrogen cooling. At least eight samples were tested for each combination of temperature and impact energy.

For penetration impact tests, the striker was set to a height of $1 \mathrm{~m}$ and the inner clamping diameter was $40 \mathrm{~mm}$. The mass of the striker was $8.17 \mathrm{~kg}$. The energy absorption was calculated from the surface underneath the load-displacement curve, until the load dropped to half of the peak load.

The non-penetration impact tests were performed using an $80 \mathrm{~mm}$ inner clamping diameter. The larger diameter compared to penetration tests facilitates the registration of the damaged area 
afterwards. The mass of the striker was $3.17 \mathrm{~kg}$ and the impact energy was set to $10 \mathrm{~J}$.

\subsection{Ultrasonic C-scan}

The non-penetration impact samples were analysed after the impact event using ultrasonic C-scans. The impacted samples were immersed in demineralised water and scanned with an Olympus Panametrics V309SU transducer at a $5 \mathrm{MHz}$ frequency and $13 \mathrm{~mm}$ nominal diameter. The scan rate was $0.2 \mathrm{~mm} / \mathrm{s}$ at a $1 \mathrm{~mm}$ step size. The obtained greyscale values from 0 to 255 were converted into black and white by setting the threshold to 128 . To obtain the damaged area, the number of black pixels were counted and multiplied by $1 \mathrm{~mm}^{2}$, which was the area of one pixel. The central damage was taken into account, while damage near the clamp or dark areas due to the supports in the corners were not taken into account.

\subsection{Wide angle $X$-ray diffraction and small angle $X$-ray scattering}

Wide angle X-ray diffraction (WAXD) and small angle X-ray scattering (SAXS) patterns were collected on the PP tapes before and after the annealing treatment. They were collected using a XeuSS setup including a GeniX 3D molybdenum point source at a power of $50 \mathrm{kV}-1 \mathrm{~mA}$. The collimation of the X-rays until a crosssection of $300 \mu \mathrm{m}$ was attained by two pairs of scattering splits. The collimation path was under vacuum. The diffracted Mo K $\alpha$ X-ray photons with a wavelength of $0.71 \AA$ A were gathered on a 2D image plate detector Mar345 (MARresearch). The combination of molybdenum rays with an appropriate collimation and a large image plate detector allowed us to simultaneously gather WAXD and SAXS data, with a q range of $0.02 \AA^{-1}-4.25 \AA^{-1}$. This correlated to a distance sensitivity between $1.5 \AA^{-1}$ (WAXD) and $300 \AA^{-1}$ (SAXS). Scattered intensities were accumulated for $3600 \mathrm{~s}$. A background pattern, caused by scattering of the equipment itself, was subtracted from the final scattering patterns, taking into account the sample transmission.

\section{Results}

\subsection{Influence of temperature on tape tensile properties}

Tensile tests were performed on the tapes as well as on the matrix. Three different temperatures were used to analyse how the tensile properties changed with temperature.

Fig. 1a demonstrates that the tape tensile modulus increases from 10 to $15 \mathrm{GPa}$ when decreasing the test temperature from $20{ }^{\circ} \mathrm{C}$ to $-40^{\circ} \mathrm{C}$. The matrix tensile modulus follows a similar but more pronounced trend: it increases from 1.7 to $4.4 \mathrm{GPa}$. This rise in properties is related to the $\beta$ glass transition of $\mathrm{PP}$, which occurs around $0{ }^{\circ} \mathrm{C}$ and immobilises the amorphous fraction of the polymer [19]. Since this fraction is larger in the matrix, it is more sensitive to the temperature change.

Fig. $1 \mathrm{~b}$ demonstrates a similar trend for the tensile strength. The tape tensile strength increases by about $25 \%$ with decreasing temperature, while the matrix strength dramatically increases. The lower chain mobility increases tensile strength, but also decreases the failure strain. Fig. 1c displays the decrease in failure strain with decreasing temperature. By going through the glass transition, the amorphous fraction of matrix and tapes embrittles. While the matrix samples do not break at $20^{\circ} \mathrm{C}$ even after a strain of $25 \%$, the failure strain is reduced to $7 \%$ and $3 \%$ at $-10{ }^{\circ} \mathrm{C}$ and $-40{ }^{\circ} \mathrm{C}$ respectively. These values are lower than the tape failure strain, which is not affected by temperature.
Fig. $1 \mathrm{~d}$ shows the energy absorbed during the tensile test. This is calculated as the area underneath the stress-strain diagram and gives an indication for the energy per unit volume required to break the sample. The absorbed energy of the tapes remains unaffected by the temperature. The embrittlement of the amorphous fraction causes a large decrease in the absorbed energy for the matrix.

The tensile properties of the matrix are significantly affected by the temperature, while the tapes remain largely unaffected. To further understand the failure behaviour of SRPP, two more aspects will be investigated. Firstly, the tested tapes might not be representative for the tapes as they are present in the SRPP. During hot compaction, the crystallinity and mechanical properties of the tapes may change. Secondly, the test temperature may also influence the tape-matrix interface. Both aspects will be investigated in the next sections.

\subsection{Influence of annealing on tape tensile properties}

Annealing treatments under tension were performed at five different temperatures to assess the influence of hot compaction on the mechanical properties of the tapes. This yields information on the mechanical properties that tapes have in the compacted SRPP.

Fig. 2a demonstrates the evolution of the tensile modulus with annealing temperature. As expected, the modulus decreases, as the annealing allows the tie molecules to relax [28]. The samples annealed at $190^{\circ} \mathrm{C}$ seem to have a higher tensile modulus than the samples annealed at $182{ }^{\circ} \mathrm{C}$ and $186^{\circ} \mathrm{C}$. This may be explained by the high temperature which could allow further drawing of the tapes.

Fig. 2b shows that the tensile strength remains largely unaffected. Tensile strength is mainly related to the crystal size and perfection and not to the tie molecules [29]. Fig. 2c and d display an increasing trend in the failure strain and absorbed energy with increased annealing temperature. The relaxation of the tie molecules allows a larger deformation prior to failure. This also increases the amount of energy that can be absorbed, at the cost of reduced stiffness. The further drawing that was used to explain the higher tensile modulus at $190{ }^{\circ} \mathrm{C}$, could be expected to lead to a decreased failure strain. Such decrease is not observed in Fig. 2c, indicating the complex balance between further drawing and increased molecular relaxation at temperatures near the melting point.

WAXD and SAXS measurements were performed to study the crystal structure of the PP tapes and the influence of the annealing treatment on the crystal structure. The specific crystal structure of oriented polymers generally consists of two distinctive features; crystal blocks arranged in microfibrils in the drawing direction and bands transverse to the drawing direction connecting the microfibrils to each other $[24,30]$. The thickness of the transverse bands represents the crystal thickness, whereas the lateral size of the crystals describes the diameter of the transverse bands. The repeat distance is the distance between these different bands.

Fig. 3 displays an example WADS/SAXS diagram of a drawn and annealed tape. The reflected peaks are dots or elongated dots instead of arcs. This is typical for an almost perfect orientation.

Fig. 4 shows the WAXD/SAXS reflections for the untreated tape and three of the annealed tapes. For an improved visualisation, it focuses on the three reflections in the middle. The measured WAXD and SAXS patterns for the PP tapes before and after annealing confirm that the crystals in the tape maintain their orientation during annealing. When the reflections for the reference and annealed tapes are compared, it can be seen that annealing tends to narrow the peaks in the horizontal direction and widen them in the vertical direction. This phenomenon originates from lateral 


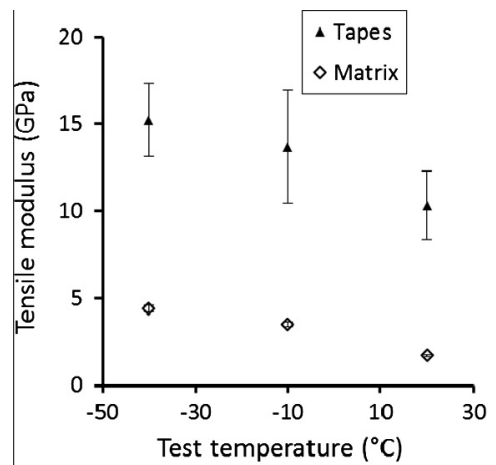

(a)

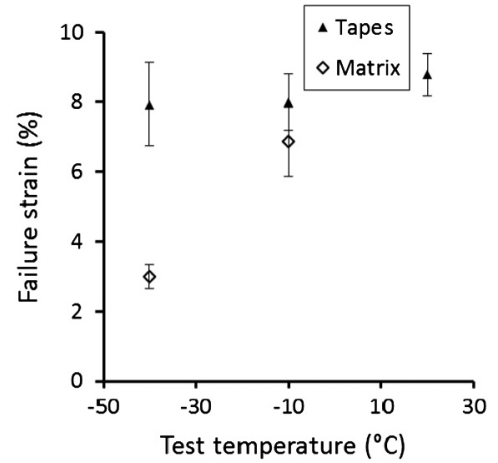

(c)

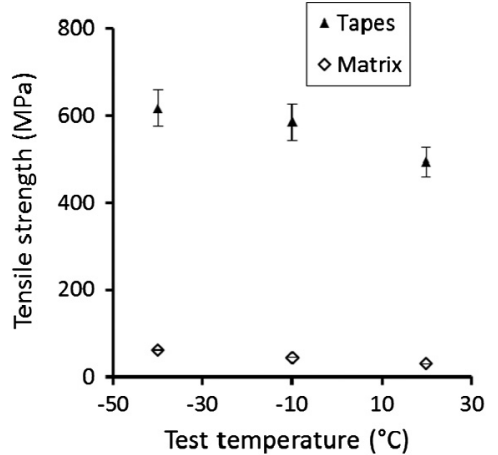

(b)

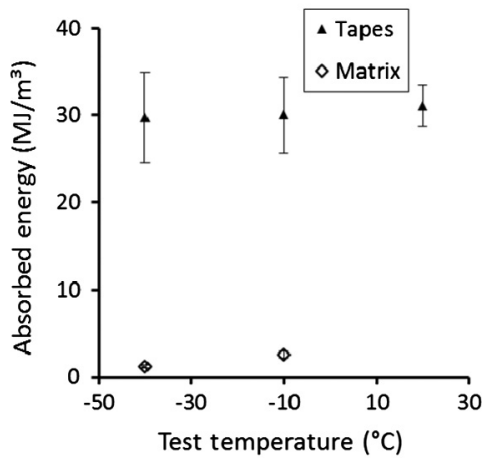

(d)

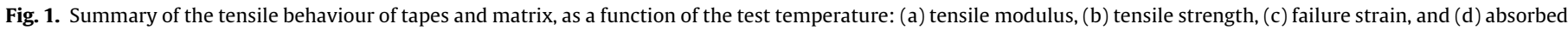
energy. Failure strain and absorbed energy for the matrix at $20^{\circ} \mathrm{C}$ was omitted, as failure did not occur before $25 \%$ strain.

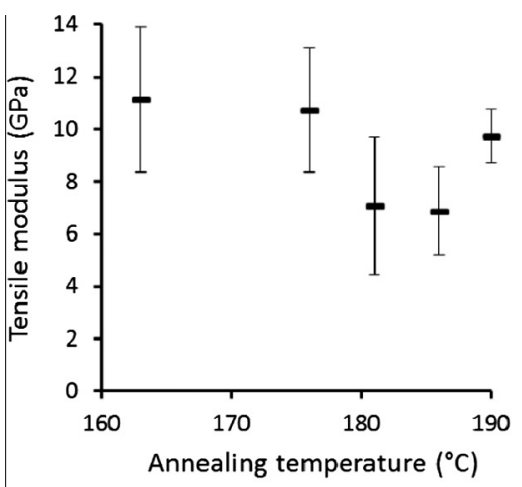

(a)

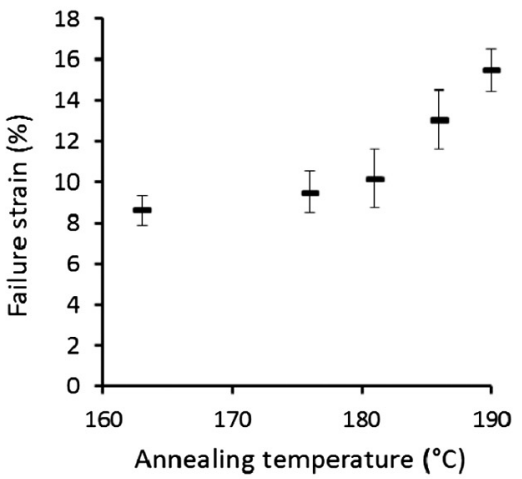

(c)

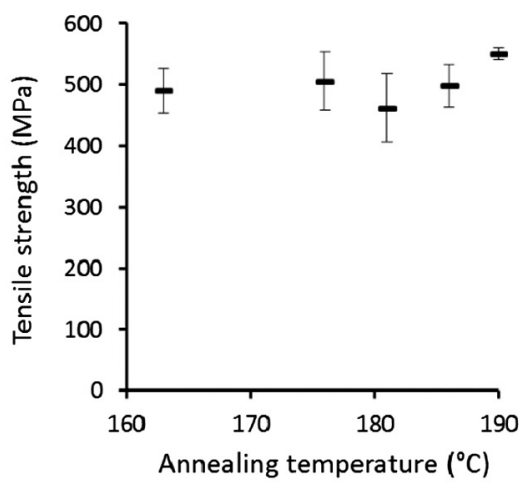

(b)

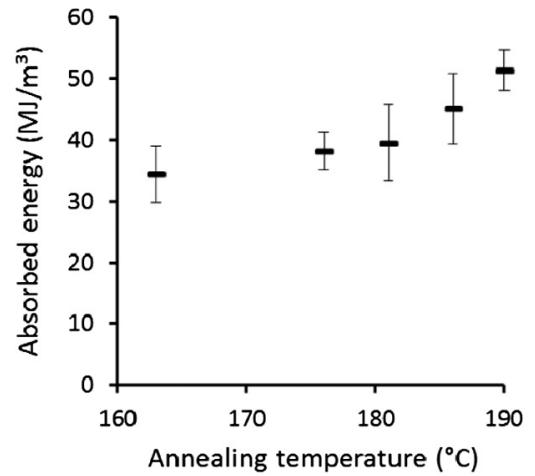

(d)

Fig. 2. Influence of the annealing treatment on the (a) tensile modulus, (b) tensile strength, (c) failure strain, and (d) absorbed energy of the tapes. 


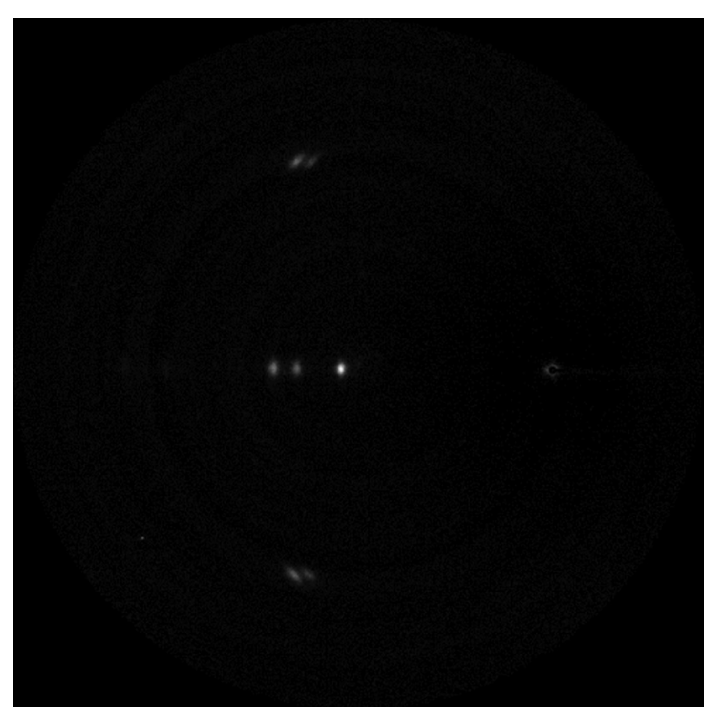

Fig. 3. Example of full WAXD/SAXS reflections on an annealed PP tape. The white circle on the right hand side is the beam stop.

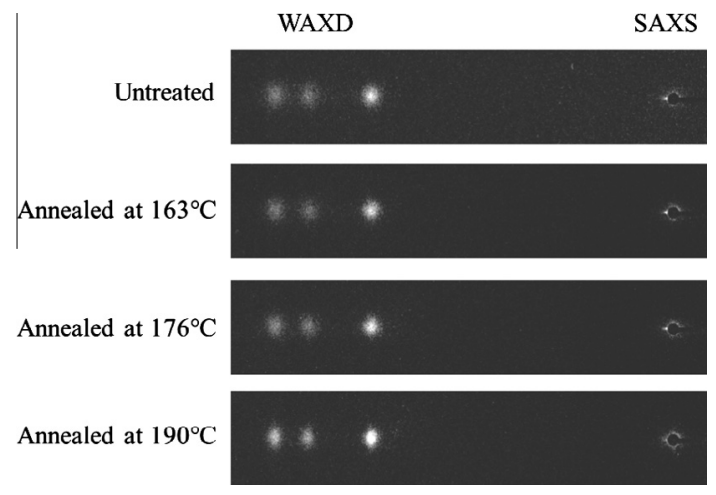

Fig. 4. WAXD and SAXS patterns for untreated and annealed PP tapes.

growth of the crystals during the annealing treatment, and an increase of their thickness. The SAXS peak is smaller than the beam stop and therefore barely visible. A peak with the size of the beam stop would indicate a thickness and a repeat distance of $30 \mathrm{~nm}$, hence the repeat distance and the lateral thickness of the crystals are both larger than $30 \mathrm{~nm}$.

The WAXD/SAXS measurements confirm that the loss in modulus and increase in failure strain is not caused by changes to the crystals. Therefore, changes to the tie molecules can be held responsible for this change in properties. Moreover, the WAXD/ SAXS measurements confirm that the crystals have not been significantly affected by the annealing treatment. This explains why the tensile strength was not significantly affected by the annealing treatment.

\subsection{Influence of temperature on SRPP tensile properties}

The previous section analysed the influence of the annealing treatment on the tapes. This yields an estimate of the tape properties as they are in the hot compacted SRPP. It is, however, difficult to estimate this, as the processing conditions during hot compaction are complex. Firstly, the shrinkage of the PP tapes is prevented by the applied hot compaction pressure, while the annealing treatment replaced this by tension. Secondly, the dwell times in the annealing treatment were shorter than in the hot compaction process, due to limitations of the equipment. Therefore, it is unclear which annealing temperature yields the best prediction of those tapes. To establish this relationship, the tensile properties of the hot compacted SRPP need to be studied at different test temperatures, as was done previously for the tapes and matrix separately.

The results for the hot compacted SRPP sheets are summarised in Fig. 5. The tensile modulus demonstrates a strong increase with decreasing test temperature. The increase in strength is smaller and counterbalanced by a decrease in the failure strain. This results in the same absorbed energy for all three temperatures, as expected from Fig. 1d. This confirms that breaking SRPP in tension requires the same energy at all three tested temperatures.

The SRPP tensile modulus can be predicted, using the approach proposed by Hine et al. [13]. Their equations are refined by taking the transverse modulus of the tapes into account. Since the hot compacted SRPP is a balanced woven sheet, conceptually the sheet can be split up into two unidirectional sheets with an equal volume: a longitudinal and a transverse sheet. The properties of the woven and compacted sheet can be reasonably approximated by the average for the longitudinal and transverse SRPP. The overall SRPP stiffness $E_{S R P P}$ can be calculated by averaging the longitudinal and transverse modulus $E_{L}$ and $E_{T}$ of a unidirectional SRPP:

$E_{S R P P}=\frac{E_{L}+E_{T}}{2}$

The equations for $E_{L}$ and $E_{T}$ are based on linear and inverse ruleof-mixtures, respectively:

$$
\begin{aligned}
& E_{L}=E_{L, t} \cdot V_{t}+E_{m} \cdot\left(1-V_{t}\right) \\
& E_{T}=\frac{E_{T, t} \cdot E_{m}}{E_{T, t} \cdot\left(1-V_{t}\right)+E_{m} \cdot V_{t}}
\end{aligned}
$$

with $E_{L, t}$ the longitudinal tape modulus, $E_{T, t}$ the transverse tape modulus, $E_{m}$ the matrix modulus, and $V_{t}$ the volume fraction of tapes. $E_{L, t}$ was taken from Fig. $2 \mathrm{a}$, while data in Fig. 1a were used for $E_{m}$. The volume fraction $V_{t}$ of tapes is difficult to measure due to the similar physical properties of tapes and matrix. $V_{t}$ is therefore assumed to be $70 \%$, as in [13]. The transverse tape modulus $E_{T, t}$ can be estimated to be $1 \mathrm{GPa}$ at $20^{\circ} \mathrm{C}$ [29] and is assumed to be independent of the annealing treatment. The results are summarised in Table 1 . The annealing treatments at $163^{\circ} \mathrm{C}$ and $176{ }^{\circ} \mathrm{C}$ yield an overestimation, meaning these annealing temperatures are not representative of the real hot compaction process. Based on these arguments, it is not possible to determine the most representative annealing treatment, but it is higher than $176{ }^{\circ} \mathrm{C}$.

Another argument for finding the most representative annealing temperature is based on the failure strains. At $20^{\circ} \mathrm{C}$, the SRPP failure strain is $19 \%$, which coincides with failure of the tapes. The failure strain of annealed tapes in Fig. 2c displays the highest value at $190{ }^{\circ} \mathrm{C}$, namely $15.5 \%$, meaning that this annealing treatment should closely resemble the temperatures used in the hot compaction process. The difference between the failure strain of $15.5 \%$ for the annealed tape at $190{ }^{\circ} \mathrm{C}$ and $19 \%$ for the SRPP can be caused by the out-of-plane orientation of the tapes in the SRPP.

\subsection{Peel strength}

The peel strength results are summarised in Fig. 6. The peel strength at $20^{\circ} \mathrm{C}$ is slightly lower than at $-10^{\circ} \mathrm{C}$ and $-40{ }^{\circ} \mathrm{C}$. The $p$-values are 0.002 and 0.02 respectively, meaning that the differences are statistically significant. It is not clear what is causing this difference, as a more brittle matrix at low temperature should in principle cause a lower peel strength. This may be caused by edge effects, as the transverse tapes at the edges are being pulled loose during the peel strength test [8]. This phenomenon may be more 


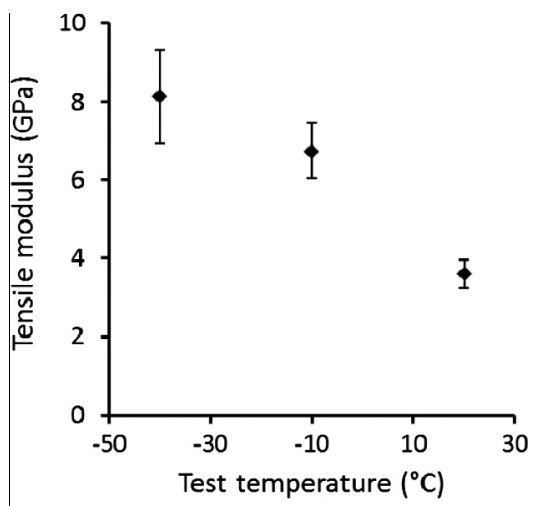

(a)

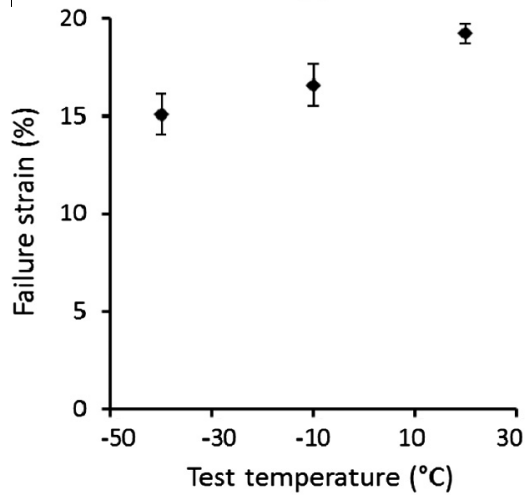

(c)

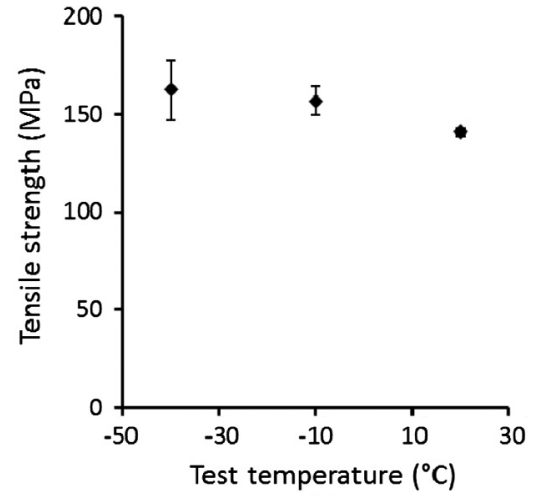

(b)

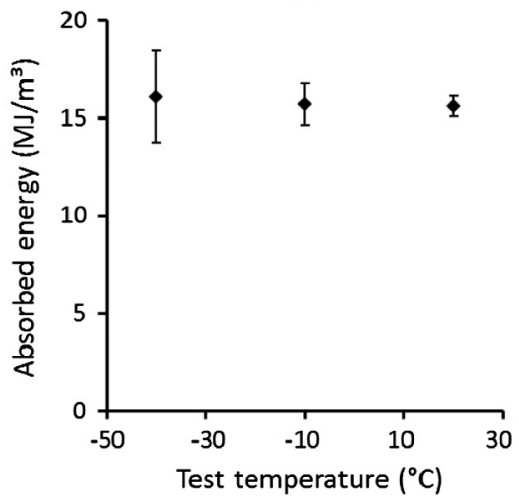

(d)

Fig. 5. Summary of the tensile behaviour of hot compacted SRPP: (a) tensile modulus, (b) tensile strength, (c) failure strain, and (d) absorbed energy.

Table 1

Predicted SRPP stiffness for the various annealing treatments. The last column contains the experimentally measured SRPP stiffness.

\begin{tabular}{lllll}
\hline Annealing treatment $\left({ }^{\circ} \mathrm{C}\right)$ & $E_{L}(\mathrm{GPa})$ & $E_{T}(\mathrm{GPa})$ & $E_{S R P P}(\mathrm{GPa})$ & Experiment $(\mathrm{GPa})$ \\
\hline 163 & 8.3 & 1.14 & 4.7 & $3.6 \pm 0.4$ \\
176 & 8.0 & 1.14 & 4.6 & $3.6 \pm 0.4$ \\
182 & 5.5 & 1.14 & 3.3 & $3.6 \pm 0.4$ \\
186 & 5.3 & 1.14 & 3.2 & $3.6 \pm 0.4$ \\
190 & 7.3 & 1.14 & 4.2 & $3.6 \pm 0.4$ \\
\hline
\end{tabular}

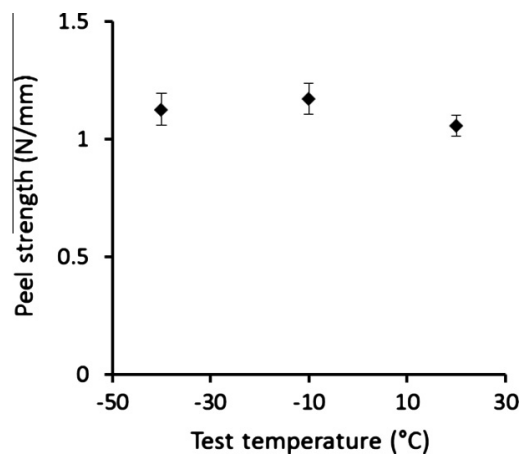

Fig. 6. The influence of test temperature on the peel strength of SRPP.

difficult at lower temperatures due to the higher strength of the tapes. In any case, the interlayer bonding is only slightly affected by the test temperature.

\subsection{Impact resistance}

Literature has proven that the impact resistance of SRPP increased at low temperature $[1,21]$. This conclusion was, however,

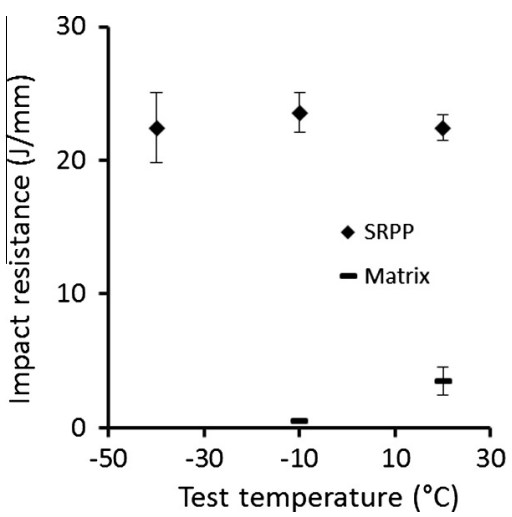

Fig. 7. Penetration impact resistance of SRPP and matrix. The value for the matrix at $-40^{\circ} \mathrm{C}$ is not shown, as it was too low to be measurable.

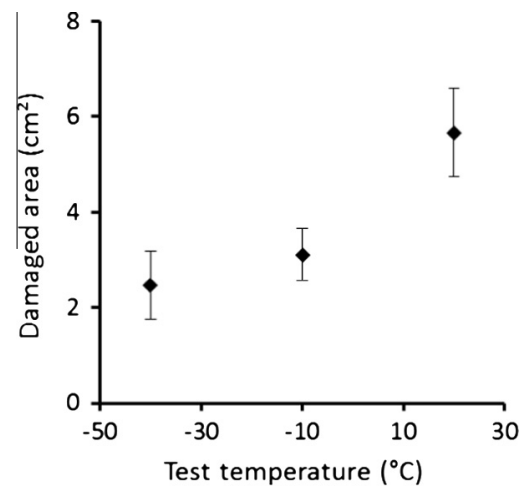

Fig. 8. Damaged area in SRPP after a non-penetration impact event 


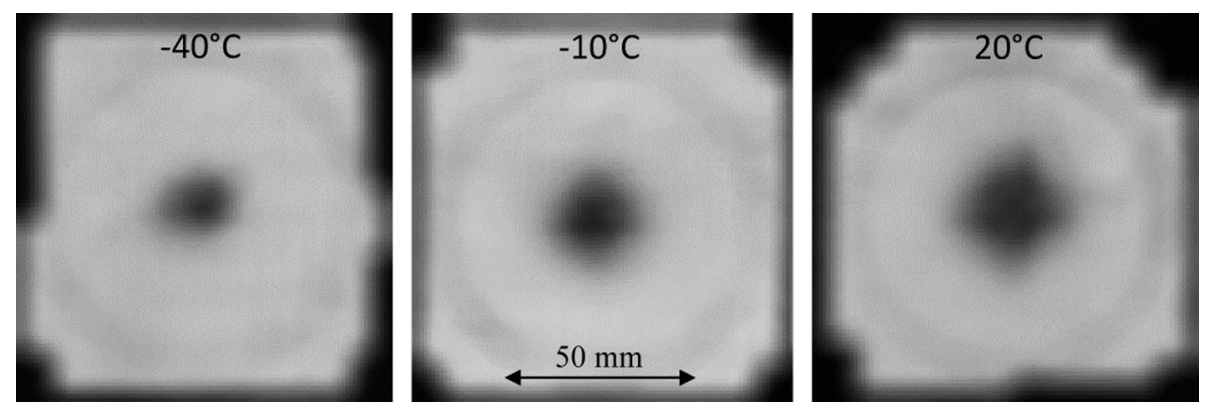

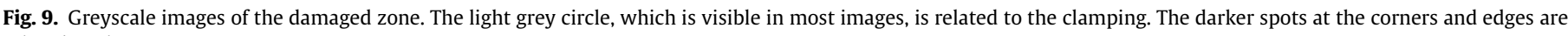
related to the supports.

drawn from notched Izod impact tests. Falling weight impact resistance is more representative for practical applications, and is hence a more common test for composites. A more complete understanding of the SRPP impact resistance becomes possible by combining both penetration and non-penetration impact tests. The tensile and peel strength properties in the previous sections will aid in explaining the observed trends.

The penetration impact resistance at three different test temperatures is plotted in Fig. 7. No statistically significant differences can be detected with a 95\% confidence level. From these results, it is clear that the penetration impact resistance remains unaffected in the temperature range of $-40{ }^{\circ} \mathrm{C}$ to $+20^{\circ} \mathrm{C}$. The PP matrix embrittles at the glass transition temperature, which is around $-10^{\circ} \mathrm{C}$. This is reflected in the dramatic decrease of the matrix impact resistance with decreasing temperature. Penetration impact resistance of SRPP is, however, dominated by tape fracture and debonding. Since both the mechanical properties of the tapes and the peel strength remained largely unaffected, the impact resistance is also unaffected by the temperature. These conclusions are in contrast with the notched Izod results from literature [1,21], which showed an increase at low temperatures. The notch introduces a triaxial stress state, which is complex to analyse and understand. This is expected to influence the damage mode, but it is unclear what the main damage mode would be.

The results of the non-penetration impact tests are summarised in Fig. 8 and visualised in Fig. 9. Both figures show that the damaged area decreases when the temperature decreases from $20^{\circ} \mathrm{C}$ to $-40^{\circ} \mathrm{C}$. Fig. 9 also demonstrates a more cross-shaped damaged area at room temperature, while the damage becomes circular at lower temperatures. The cross-shaped damage indicates a damage mode that involves the tapes: tape fracture or tape-matrix debonding. Due to the high failure strain of the tapes and the low impact energy, tape fracture seems unlikely, making tape-matrix debonding the dominant mechanism. At low temperatures, however, the circular damage indicates that most of the damage is located in the matrix, and tape-matrix debonding is less pronounced.

At low temperature, the matrix embrittles and becomes stiffer (see Fig. 1), and the interlayer bonding slightly decreases (see Fig. 6). The matrix embrittlement changes the damage mechanism from tape debonding to matrix cracking, while the stiffening causes the impact event to be more localised. The slightly increased interlayer bonding can help to explain the lower damaged area at low temperatures, but this increase is most likely too small to contribute significantly to the trend observed in Fig. 8.

\section{Conclusions}

The failure behaviour of SRPP at low temperatures was explained for the first time. Tensile tests showed that the tapes are only slightly affected by temperature, while the matrix is dramatically affected as it goes through its glass transition. The interlayer bonding, measured by peel strength tests, was only slightly affected by temperature. These observations are crucial for explaining the impact resistance at low temperatures.

The energy absorption in penetration impact is dominated by the tapes. Since they maintain their mechanical properties at low temperatures, the penetration impact resistance was unaffected by the test temperature. This is in contrast with literature data on notched Izod impact tests, which showed a $50 \%$ increase at $-40^{\circ} \mathrm{C}$. Interestingly, the test temperature was indeed crucial for non-penetration impact resistance. The damaged area strongly decreased when tested below room temperature. At room temperature, tape-matrix debonding dominates, resulting in a large damaged area. This damage mode changes to matrix cracking at lower temperature, causing a more circular damage pattern. Combined with the higher SRPP stiffness at low temperature, this causes a smaller damaged area.

Fine-tuning of the matrix failure strain can improve the damage resistance of self-reinforced polymers. A more brittle PP grade for the matrix, for example, can be useful to limit the damaged area after non-penetration impact events. In the case of hot compacted SRPP, however, this optimisation is not straightforward, as changing the PP grade would also change the tape properties.

\section{Acknowledgements}

The authors thank the Agency for Innovation by Science and Technology in Flanders (IWT) for the grant of Y. Swolfs. The authors would like to thank Bart Goderis and Maja Vanhalle for their help with the WAXD/SAXS measurements. I. Verpoest holds the Toray Chair in Composite Materials at KU Leuven.

\section{References}

[1] Ward IM, Hine PJ. The science and technology of hot compaction. Polymer 2004:45(5):1413-27.

[2] Gao C, Yu L, Liu H, Chen L. Development of self-reinforced polymer composites. Prog Polym Sci 2012;37(6):767-80.

[3] Karger-Kocsis J, Bárány T. Single-polymer composites (SPCs): status and future trends. Compos Sci Technol 2014;92:77-94.

[4] Schimanski T, Loos J, Peijs T, Alcock B, Lemstra PJ. On the overdrawing of meltspun isotactic polypropylene tapes. J Appl Polym Sci 2007;103(5):2920-31.

[5] Schimanski T, Peijs T, Lemstra PJ, Loos J. Influence of postdrawing temperature on mechanical properties of melt-spun isotactic polypropylene. Macromolecules 2004;37(5):1810-5.

[6] Hine PJ, Ward IM, Teckoe J. The hot compaction of woven polypropylene tapes. J Mater Sci 1998;33(11):2725-33.

[7] Alcock B, Cabrera N, Barkoula N, Spoelstra A, Loos J, Peijs T. The mechanical properties of woven tape all-polypropylene composites. Compos A Appl Sci Manuf 2007:38(1):147-61.

[8] Swolfs Y, Crauwels L, Gorbatikh L, Verpoest I. The influence of weave architecture on the mechanical properties of self-reinforced polypropylene. Compos A Appl Sci Manuf 2013;53:129-36.

[9] Bárány T, Karger-Kocsis J, Czigány T. Development and characterization of selfreinforced poly(propylene) composites: carded mat reinforcement. Polym Adv Technol 2006;17(9-10):818-24. 
[10] Marais C, Feillard P. Manufacturing and mechanical characterization of unidirectional polyethylene-fiber polyethylene-matrix composites. Compos Sci Technol 1992;45(3):247-55.

[11] Cabrera N, Alcock B, Loos J, Peijs T. Processing of all-polypropylene composites for ultimate recyclability. Proc Inst Mech Eng Part L - J Mater-Des App 2004;218(L2):145-55.

[12] Alcock B, Cabrera NO, Barkoula NM, Peijs T. Low velocity impact performance of recyclable all-polypropylene composites. Compos Sci Technol 2006;66(1112):1724-37.

[13] Hine PJ, Ward IM, Jordan ND, Olley R, Bassett DC. The hot compaction behaviour of woven oriented polypropylene fibres and tapes. I. Mechanical properties. Polymer 2003;44(4):1117-31.

[14] Jordan ND, Bassett DC, Olley RH, Hine PJ, Ward IM. The hot compaction behaviour of woven oriented polypropylene fibres and tapes. II. Morphology of cloths before and after compaction. Polymer 2003;44(4):1133-43.

[15] Swolfs Y, Crauwels L, Van Breda E, Gorbatikh L, Hine P, Ward I, et al. Tensile behaviour of intralayer hybrid composites of carbon fibre and self-reinforced polypropylene. Compos A Appl Sci Manuf 2014;59:78-84.

[16] Verpoest I, Lomov S, Swolfs Y, Jacquet P, Michaud V, Manson J-A, et al. Advanced materials enabling high-volume road transport applications of lightweight structural composite parts. Sampe J 2014;50(3):30-7.

[17] Hine P, Bonner M, Ward I, Swolfs Y, Verpoest I, Mierzwa A. Hybrid carbon fibre/nylon 12 single polymer composites. Compos A Appl Sci Manuf 2014 http://dx.doi.org/10.1016/j.compositesa.2014.05.020.

[18] Hine PJ, Ward IM, Olley RH, Bassett DC. The hot compaction of high modulus melt-spun polyethylene fibers. J Mater Sci 1993:28(2):316-24.

[19] Schimanski T. High-performance polypropylene structures for eco-friendly, fully recyclable composite. Technische Universiteit Eindhoven; 2002.

[20] Alcock B, Cabrera NO, Barkoula NM, Peijs T. The effect of processing conditions on the mechanical properties and thermal stability of highly oriented PP tapes. Eur Polymer J 2009;45(10):2878-94.
[21] Jones RS, Riley DE. A new self-reinforced polypropylene composite. In: Proceedings of the 2nd annual conference of society of plastics engineers, automotive and composites division. Michigan, USA; 2002.

[22] Loos J, Schimanski T. Effect of postdrawing temperature on structure, morphology, and mechanical properties of melt-spun isotactic polypropylene tapes. Macromolecules 2005;38(26):10678-85.

[23] Teckoe J, Olley RH, Bassett DC, Hine PJ, Ward IM. The morphology of woven polypropylene tapes compacted at temperatures above and below optimum. J Mater Sci 1999;34(9):2065-73.

[24] Amornsakchai T, Bassett DC, Olley RH, Hine PJ, Ward IM. On morphologies developed during two-dimensional compaction of woven polypropylene tapes. J Appl Polym Sci 2000;78(4):787-93.

[25] Hine PJ, Unwin AP, Ward IM. The use of an interleaved film for optimising the properties of hot compacted polyethylene single polymer composites. Polymer 2011;52(13):2891-8.

[26] Hine P, Olley R, Ward I. The use of interleaved films for optimising the production and properties of hot compacted, self reinforced polymer composites. Compos Sci Technol 2008;68(6):1413-21.

[27] Swolfs Y, Zhang Q, Baets J, Verpoest I. The influence of process parameters on the properties of hot compacted self-reinforced polypropylene composites. Compos A Appl Sci Manuf 2014. http://dx.doi.org/10.1016/j.compositesa.2014. 05.022 .

[28] Seguela R. Critical review of the molecular topology of semicrystalline polymers: the origin and assessment of intercrystalline tie molecules and chain entanglements. J Polym Sci Pt B-Polym Phys 2005;43(14):1729-48.

[29] Ward IM, Sweeney J. Mechanical properties of solid polymers. 2nd ed. Chichester: Wiley; 2004.

[30] Peterlin A. Molecular model of drawing polyethylene and polypropylene. J Mater Sci 1971;6(6). p. 490. 